\title{
Digital Healthy Lifestyle Application for UUM Computer User
}

https://doi.org/10.3991/ijim.v15i06.20675

\author{
Azliza Othman ${ }^{\square}$, Nassiriah Shaari, Yusrita Mohd. Yusoff \\ Universiti Utara Malaysia, Sintok, Malaysia \\ azlizaman26@outlook.com
}

\begin{abstract}
A computer is a vital tool for UUM community in doing routine jobs and activities. Spending many hours using a computer without breaks can cause bad effect on users' health. Inappropriate computer use can cause muscle and joint pain, overuse injuries of the shoulder, arm, wrist or hand, and eyestrain. Fortunately, this pain and misery can be avoided with only a few simple routines. Therefore, a short break from using a computer is necessary. The break could be filled with a short and simple exercise. Physical exercise can provide many benefits to individual and organization. Besides improving the productivity of the organization, physical exercise also can help staff and students to be more focused, stay alert, feel motivated, energetic, and have less stress. In response to this, this paper introduces a digital health application to create health awareness among the UUM community. The methods employed in the study are a preliminary investigation, requirement gathering and analysis, prototype development, and prototype validation. From the requirement analysis phase, 11 criteria were gathered and applied in designing the Digital Healthy Lifestyle Application prototype. Then it was validated by the content and user interface experts. The experts responded positively towards the application.
\end{abstract}

Keywords - Digital application, healthy lifestyle, UUM Community

\section{$1 \quad$ Introduction}

Universiti Utara Malaysia (UUM) has a large community consisting of lecturers, administrative staff, students, and general workers. Normally, the lecturers and administrative staff work for 8 to 10 hours daily in which they have to use computers. Lecturers use the computer for teaching preparation and searching reference for their discussion, research, and publication while administrative staff use the computer for most of their work since all the management systems are computer-based. Students use computers for their learning and personal matters.

A mojority of UUM community usea computer for their routine jobs and activities. Spending many hours using a computer without a break can cause negative effects on users' health.Excessive computer use can lead tomuscle and joint pain, overuse injuries of the shoulder, arm, wrist or hand, and eyestrain [10][19]. Also, a study by [14] as cited in [18] reported that staring at a bright screen for hours can causeeye fatigue or 
eye strain, headaches, blurred vision, burning, itching or tearing eyes, and temporary vision disorders. [17] found that high prevalence related problems of vision wasprominent among university students. There isan association between sustained periods of close screen work without screen filters with the occurrence of the symptoms and increased interruptions of students'learning activities.

Research on health and ergonomics with the use of computers have been performed in the context of working life, in line with the increasing computerization of work in the past decades. [8] stated that the increasing use of a computer could be accompanied by new health problems. It can be classified into psychological problems and physical problems. A study by [10] and [9] also found that frequent computer-related activities are an independent risk factor for neck-shoulder pain (NSP) and low back pain (LBP). Neck pain in computer users is one of the health issues faced by IT professional in India [4]. The results in [22] study on computer sleep disturbances and symptoms of depression among young adults indicate that time spent on general computer use was associated with sleep disorders and reduced performance for the men. As for women, using the computer without breaks was a threat factor for several mental health results. Besides, they also found that both men and women, who are using a computer at night and accordinglydroppingtheir sleep wereconnected with most mental health outcomes.

Fortunately, this pain and misery can be avoided with only a few simple routines. Experts suggest to take frequent short breaks, get up to walk and stretch at least once an hour, actively relax and interact with other people. Therefore, a short break from using a computer is necessary. The break could be filled with a short and simple exercise. Physical exercise can provide many benefits to individual and organization. Besides improving the productivity of the organization, physical exercise also can help staff and students to be more focused, stay alert, feel motivated, have more energy and have less stress. However, many people believe that it is difficult to exercise. This is because they believe that itis time-consuming, needs proper training and proper clothes, and can only be done in a specific time.

This paper aspires todevelop a prototype of a digital healthy lifestyle application [26][27] for UUM computer user community. It describes the design of the application based on user requirements gathered and review from experts for improvement [25].

\section{$2 \quad$ Literature Review}

[24] defined a healthy lifestyle as a way of living that lowers the risk of being seriously ill or dying early. On the other hand, health is not just about avoiding a disease or illness. It is also about physical, mental, and social well-being too. Hence a healthy lifestyle is also defined as a way of living that helps people to enjoy more aspects of their life. Besides that, adopting a healthy lifestyle can provide a more positive role model for other people, especially in the family. It will create a better environment for children to grow up in.

[6] defined a healthy lifestyle as the steps, actions, and strategies one puts in place to achieve optimum health. It is a state of complete physical, mental, and social wellbeing and not just about the absence of disease. Healthy living is about taking 
responsibility and making smart health choices for today and the future. It must be based on some basic rules which consist of the healthy and balanced nutrition, physical activity, emotional and spiritual wellness as well as prevention of health risks [6]. Neglecting these basic rules is considered an unhealthy lifestyle.

Meanwhile, the Guide to Healthy Living produced by [20] also focuses on three main elements of healthy living namely nutrition, exercises, and thoughts. The ten elements of healthy lifestyles that have been identified to be associated with reduced disease risk and increased wellness are regularphysical activity, eating well, managing stress, avoiding negative habits, adopting good safety habits, learning first aid, adopting good personal health habits, seeking and complying with medical advice, being an informed consumer, and protecting the environment. According to the list, the first three elements - regular physical activity (exercise), eating well, and managing stress are considered to be the priority of healthy lifestyles. These elements of healthy lifestyles are given higher priority because the behaviors affect people's lives. Besides that, there are lifestyles in which large numbers of people can make improvements. Modest changes in these behaviors can make dramatic improvements in individual and hence public health.

Physical activity or exercise is a broad term used to describe all types of large muscle movements. Physical activities include sports, dance, games, work, lifestyle activities, and exercise for fitness. According to $\mathrm{WHO}, 60 \%$ to $85 \%$ of the population worldwide does not engage in enough activity. [23] suggests that for substantial health benefits, adults should do at least 150 minutes ( 2 hours and 30 minutes) a week of moderateintensity, or 75 minutes (1 hour and 15 minutes) a week of vigorous-intensity aerobic physical activity, or an equivalent combination of moderate and vigorous-intensity aerobic activity. Aerobic activity should be performed in episodes of at least 10 minutes, and preferably, it should be spread throughout the week. When older adults cannot do 150 minutes of moderate-intensity aerobic activity a week because of chronic conditions, they should be as physically active as their abilities and conditions allow [12]. Previously, [16] claimed that aerobic endurance training of fewer than 2 days a week, at less than $40-50 \%$ of $\mathrm{VO}_{2} \mathrm{R}$, and for less than 10 minutes is generally not adequate for developing and maintaining fitness in healthy adults. However, many health benefits can also be achieved at lower intensities of exercise if the regularity and length of training are increased appropriately so that physical activity can be gatheredduring the day in shorter bouts of 10 minutes duration.

According to [13] as cited in [7], exercising for less than 10 minutescan result in fitness and health benefits, particularly in sedentary individuals such as computer user. When sedentary activities are broken up by shortbouts of physical activity or standing, reduction of theseadverse biological effects can occur [11], as cited in [7]. Based on this, several experts introduce exercise guidelines for computer users. The University of the Sunshine Coast has USC Ergonomic Exercises for Computer Users and Office Worker. Monash University has its community exercise guidelines for Monash officebased workers. However, both guidelines are presented in graphics and the steps are explained in text form. The complete exercise provided covers necessary parts such as the neck, shoulders, wrists, hands and arms, upper and lower back, legs, and eyes. User can read and follow the instructions provided for each step. 


\section{$3 \quad$ Method}

The methodology for this study encompasses four stages as illustrated in Fig 1.

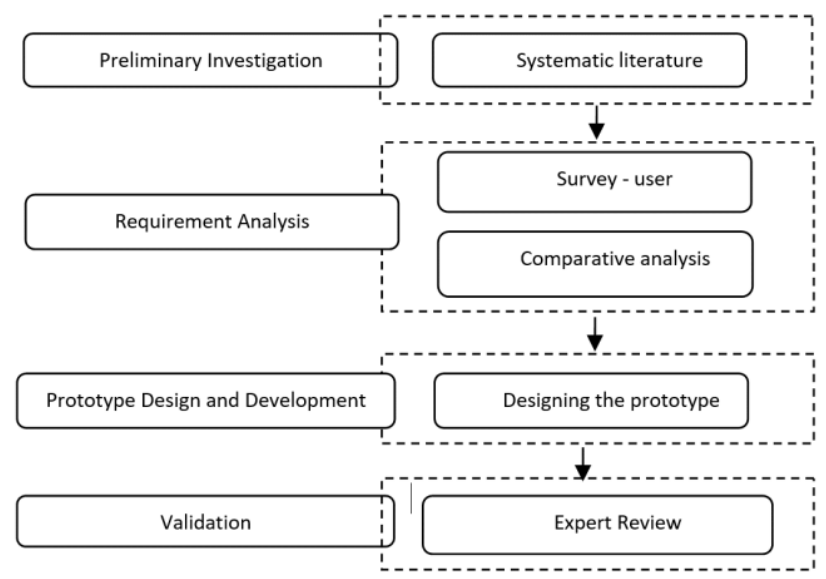

Fig. 1. Research methodology

\subsection{Preliminary investigation}

First, in the preliminary investigation phase, a review of the literature was done to identify the current situation and issues related to a healthy lifestyle and to identify the concepts and theories of persuasion that are important to influence someone's attitudes and behaviour. The literature analysis is important to ensure that all possible perspectives were taken into account before designing the application (prototype). The literature stresses that keeping a healthy lifestyle is very important to people of all ages and status and that awareness programs of living a healthy lifestyle are increasing worldwide and in Malaysia. However, some people are still having difficulty in achieving a healthy lifestyle.

\section{Requirement Gathering and Analysis}

In the requirement gathering and analysis phase, user survey and comparative analysis have been done to get user requirement for designing the application. First, we surveyed the UUM community to identify their healthy lifestyle practices and most common and widely used devices and communication media. This was done to identify suitable multimedia elements and media for our digital healthy lifestyle application.

Both Online and offline questionnaires were used and distributed to UUM community by convenience. There were 130 respondents $(99(76.15 \%)$ female and 31 $(23.85 \%)$ male). The respondents represented four categories of UUM community students $(56.15 \%)$, lecturers $(32.31 \%)$, administrators $(5.39 \%)$, and support staff 
(6.15\%). The majority of respondents are Malaysian. Fig. 2 shows the demographics of the respondents.

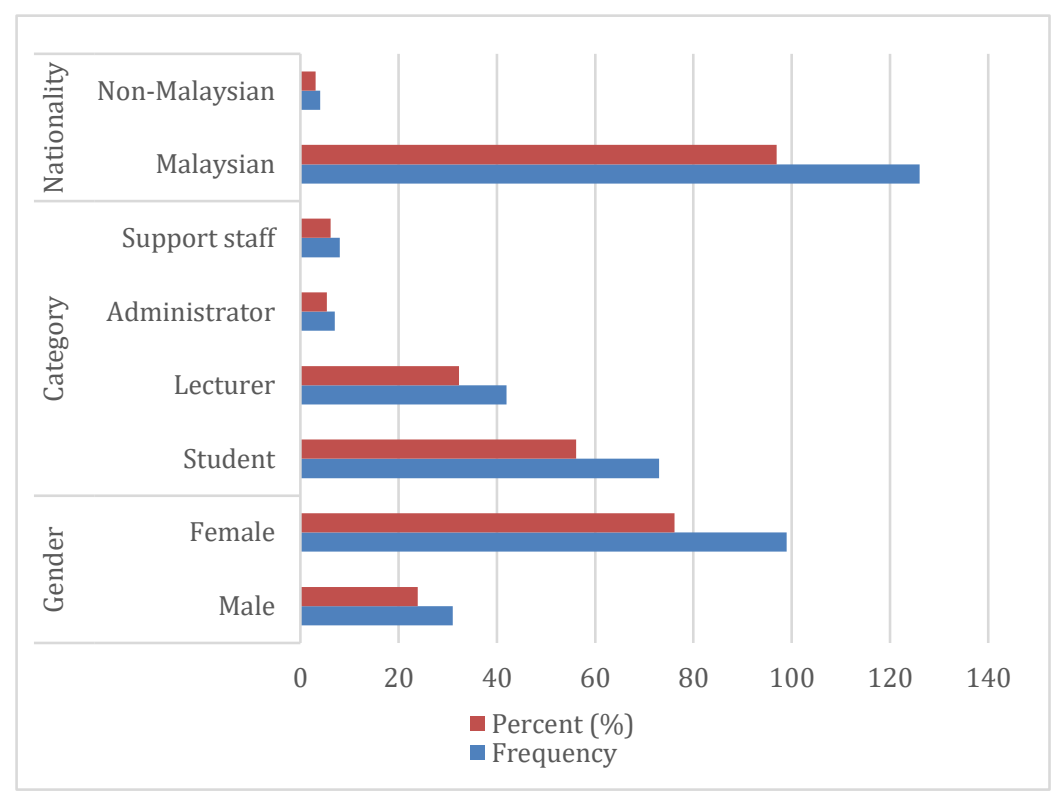

Fig. 2. Demographics of the respondents

The result reveals that on average, respondents use laptop or desktop for almost 7 hours, smartphones for nearly 10 hours, and tablet for just one and a half hours as illustrated in Table 3. Although the smartphone is the most popular device and platform used among UUM community, we chose to develop our healthy lifestyle app for laptop/desktop platform. This is because this platform needs the user to stay in one place to do their work and/or study. Moreover, spending many hours on this platform is related to unhealthy lifestyle compared to the other platforms and is a worrisome issue in the workplace.

For the design requirements, the majority of respondents agreed that, for a healthy lifestyle application, the application should be interactive, easy to use, user friendly, and has an appealing interface and useful/helpful content as shown in Fig. 3. 


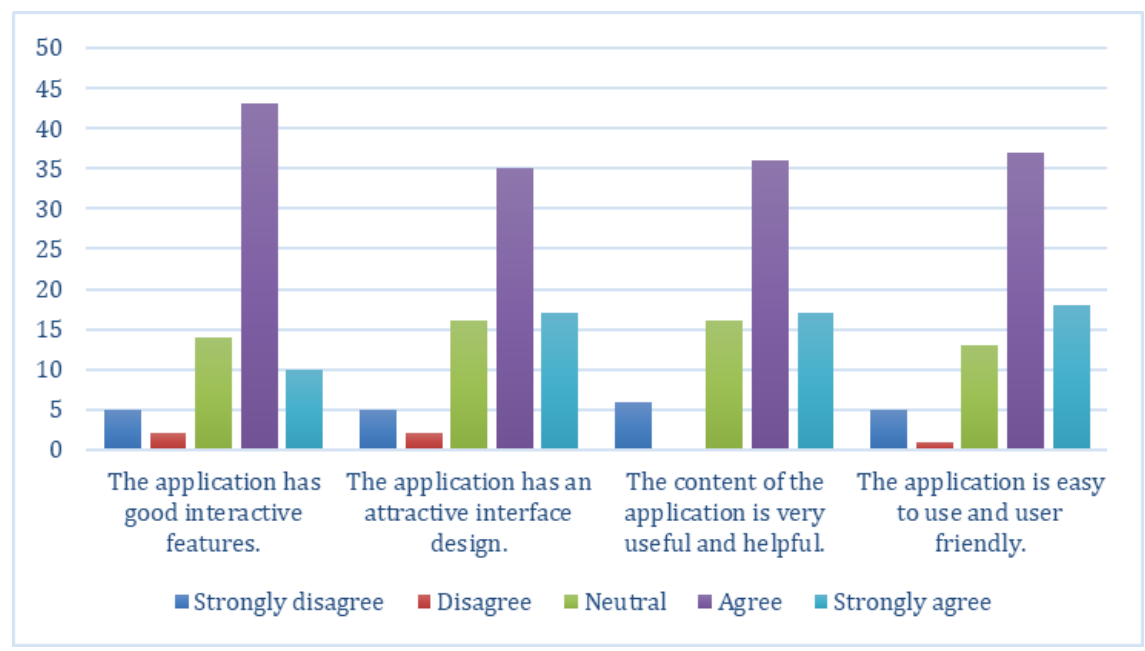

Fig. 3. Respondents' design requirement of healthy lifestyle application

To identify design requirements that users want for the digital healthy lifestyle application we asked 15 questions related to 15 design criteria as shown in Table 1.

Table 1. Application design requirement.

\begin{tabular}{|c|l|c|c|c|c|c|}
\hline No. & \multicolumn{1}{|c|}{ Application Design Requirements } & $\begin{array}{l}\text { Strongly } \\
\text { disagree }\end{array}$ & Disagree & Neutral & Agree & $\begin{array}{c}\text { Strongly } \\
\text { agree }\end{array}$ \\
\hline 1 & $\begin{array}{l}\text { I like to use an application that has a cartoon/ } \\
\text { object/ animation as a guide. }\end{array}$ & 12 & 11 & 26 & 46 & 33 \\
\hline 2 & $\begin{array}{l}\text { I like to use applications that have graphics/ } \\
\text { images that can give a brief overview on things/ } \\
\text { activities. }\end{array}$ & 7 & 3 & 15 & 54 & 49 \\
\hline 3 & $\begin{array}{l}\text { I like to use an application that has audio/ sound } \\
\text { that explains the concept/ activity. }\end{array}$ & 6 & 7 & 20 & 44 & 51 \\
\hline 4 & $\begin{array}{l}\text { I like to use applications that have background } \\
\text { music to provide more fun. }\end{array}$ & 11 & 9 & 35 & 35 & 38 \\
\hline 5 & $\begin{array}{l}\text { I like to use an application that allows me to } \\
\text { complete tasks in unlimited time. }\end{array}$ & 9 & 6 & 18 & 48 & 47 \\
\hline 6 & $\begin{array}{l}\text { I like to use applications that often give words of } \\
\text { encouragement and incentive. }\end{array}$ & 8 & 4 & 24 & 45 & 47 \\
\hline 7 & $\begin{array}{l}\text { I like to use an application that provides } \\
\text { information about my current activity. }\end{array}$ & 7 & 3 & 25 & 47 & 46 \\
\hline 8 & $\begin{array}{l}\text { I like to use an application that provides a forum } \\
\text { for discussion that allows me to share information } \\
\text { with other users. }\end{array}$ & 7 & 5 & 35 & 44 & 37 \\
\hline 9 & $\begin{array}{l}\text { I like to use applications that have soft and } \\
\text { harmonious background colors such as yellow, } \\
\text { light blue, light green and gray. }\end{array}$ & 10 & 7 & 28 & 48 & 35 \\
\hline 10 & $\begin{array}{l}\text { I like to use applications that have bright } \\
\text { background colors such as red, yellow and blue. }\end{array}$ & 16 & 31 & 44 & 22 & 15 \\
\hline $\begin{array}{l}\text { I like to use applications that have dark } \\
\text { background colors such as black and blue-black. }\end{array}$ & 24 & 26 & 29 & 28 & 21 \\
\hline
\end{tabular}




\begin{tabular}{|c|l|c|c|c|c|c|}
\hline 12 & $\begin{array}{l}\text { l like to use an application that has a font that is } \\
\text { clear and easy to understand. }\end{array}$ & 7 & 4 & 15 & 46 & 56 \\
\hline 13 & $\begin{array}{l}\text { l like to use an application that has a font that has } \\
\text { artistic writing / flowery. }\end{array}$ & 28 & 27 & 30 & 30 & 13 \\
\hline 14 & $\begin{array}{l}\text { l like to use an application that provides enough } \\
\text { time for me to learn something. }\end{array}$ & 7 & 7 & 14 & 54 & 46 \\
\hline 15 & $\begin{array}{l}\text { I like to use applications that do not force me to } \\
\text { answer questions/ perform the given activity. }\end{array}$ & 6 & 8 & 22 & 42 & 50 \\
\hline
\end{tabular}

Based on the result, of the 15 criteria, 11 criteria with positive high scores (agree and strongly agree) were applied in our paper-prototype design. Three criteria as discussed in item 10,11, and 13 were not considered in our design because of their lower positive scores.

1. Use cartoon/object/animation as a guide

2. Use graphics/images that can give a brief overview of things/ activities.

3. Use audio/sound/background music

4. Unlimited time (avoid time out)

5. Use encouragement/incentives words

6. Show the status of current activity

7. Provide forum

8. Use soft and harmonious background colors

9. Use readable font

10. Provide enough time to learn something

11. Give freedom to answer question/perform activity

Then, a comparative analysis was done to identify suitable content and design requirement for our app, in which we reviewed related health guidelines. For content, we reviewed the USC Ergonomic Exercises for Computer Users and Office Worker guidelines from the University of the Sunshine Coast and the community exercise guidelines for Monash office-based workers [15] from Monash University as references for our app content. We chose stretching and strengthening exercises for our app. We also performed a comparative analysis of existing healthy lifestyle-related apps to investigate their content, elements, scopes, strengths and limitations.

\section{$5 \quad$ Prototype Development}

In the prototype development phase, we designed a paper prototype based on the findings gathered from the preliminary investigation and requirement analysis phase. To make it simple and easy for users to understand, we adopted the less is more principle for our design. The 11 criteria of requirements from users have also been applied in the paper prototype.

Fig. 4 shows the main page of the prototype. We applied three criteria - use graphics/images that can give a brief overview on things/activities, use audio/sound/background music, and use soft and harmonious background colours in the Main page of the prototype. 


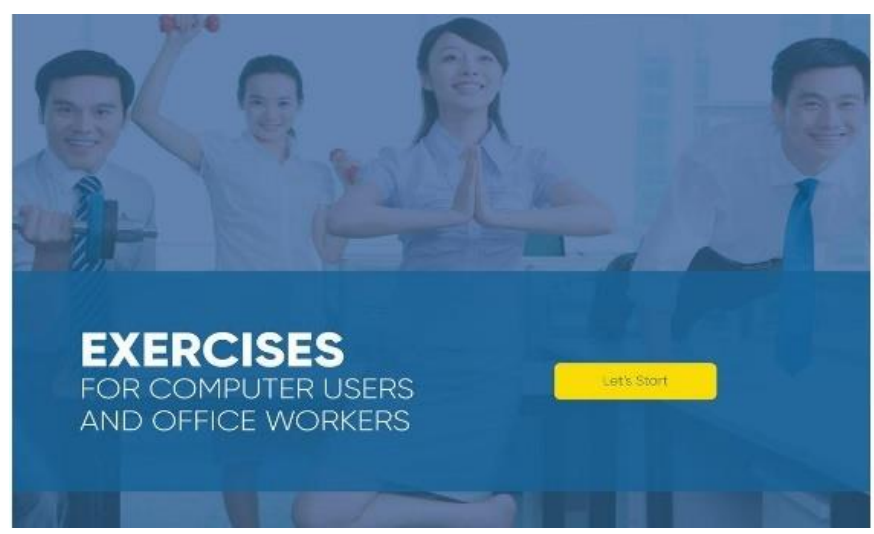

Fig. 4. The Main page

For the Exercises page, as shown in Fig. 5, we used five criteria cartoon/object/animation as a guide; graphics/images that can give a brief overview on things/activities; audio/sound/background music; soft and harmonious background colours; and give freedom to answer question/perform activity.

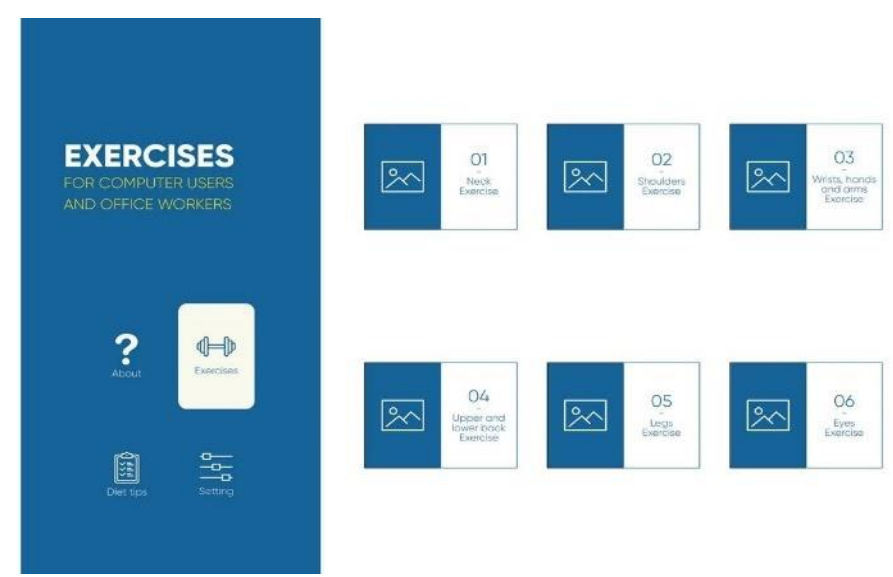

Fig. 5. The Exercise page with choices of exercises

The Exercises page offers six different exercises - Neck Exercise; Shoulder Exercise; Wrist, hands, and arms Exercise; Upper and lower back Exercise; Legs Exercise; and Eyes Exercise. All the Exercises pages have a similar design that applied all the identified 11 criteria discussed in the previous section (3.2). Fig. 6 shows one example of the page. 


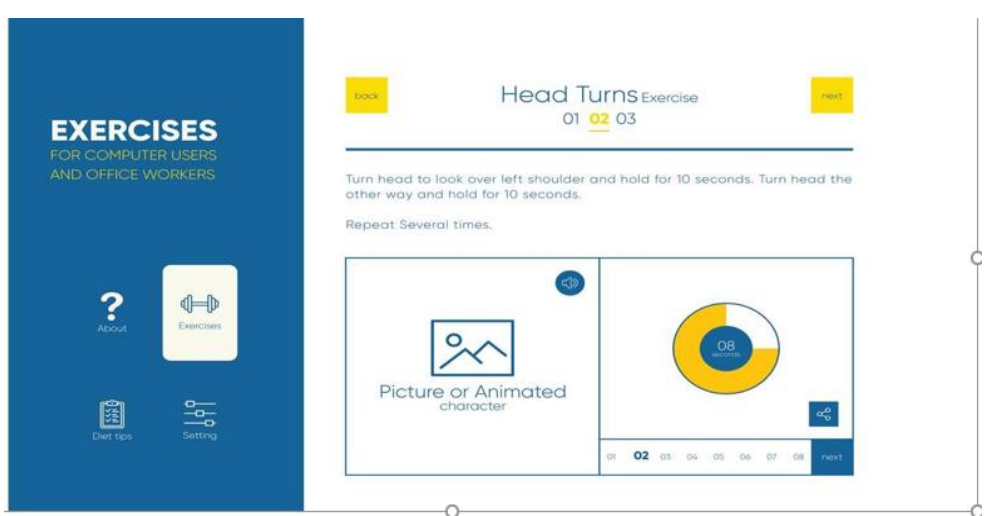

Fig. 6. An example of the Exercise page

Fig. 7 shows how the criteria of use encouragement/incentives words have been applied to the design of every completed exercise.

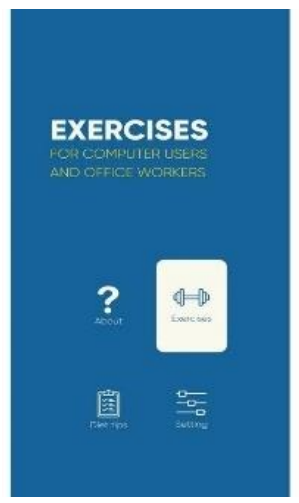

Fig. 7. Encouragement page

As people are different in many ways such as their likes, dislikes, and preferences, we provide customization and personalization feature in the Setting module. This feature helps users to personalize the app to their preferences. The app allows users to change the font size and background color as illustrated in Fig. 8. 

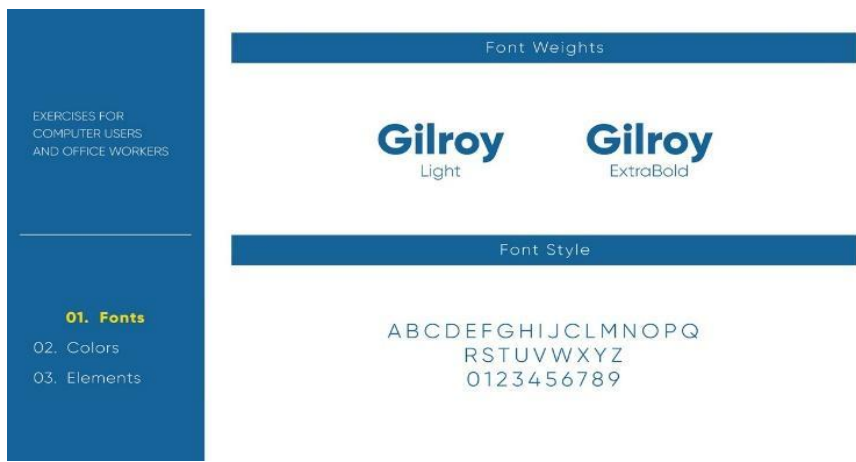

(a) The font
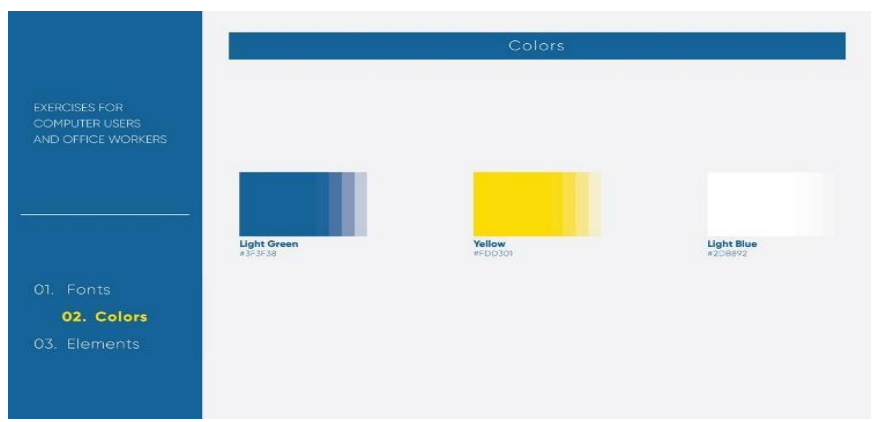

Fig. 8. (b) Background color setting interface

\subsection{Prototype validation}

In the validation phase, we employed an expert review method to review and verify the app. Two sessions were conducted; one with physiotherapists as content experts and the other with experienced interface design experts to review the user interface design, navigation, and interactivity.

\section{$6 \quad$ Result and Discussion}

In the prototype validation phase, content and user interface validation took place towards the end of the prototype lifecycle. The content experts and user interface experts went through the application and the instruments to evaluate the content, the flow, the look and feel, functionalities, and the interaction aspect. Two expert review sessions were conducted to validate the prototype.

In content validation, two physiotherapist practitioners with more than four years of working experience in physiotherapy area validated the prototype. Both content experts agreed with the prototype contents since the contents cover both stretching and strengthening exercises. Stretching or flexible exercise is a type of exercise along with strength, balance and endurance. Stretching exercises help to stretch the muscles and 
make the body maintain flexibility. These exercises can give people more freedom of movement for other exercises and also for everyday activities. It may also help people avoiding discomfort while beingrestricted in place for a long period such as while using a computer. Strengtheninggives the muscles ability to perform everyday activities and helps protect the body from injury.

Stronger muscles also lead to a boost in metabolic rate which means more calories will burn even when the body is at rest. Regular strengthening training will help people to be more capable of performing their daily tasks. Strengthening also can stimulate bone growth, lower blood sugar, assist with weight control, improve balance and posture, and reduce stress and pain in the lower back and joints. Both experts agreed that these exercises are included in a healthy workout routine and follow the American Heart Association Recommendations for Physical Activity in Adults (2020) and Physical Activity Guidelines for Americans (2018).

The experts also confirmed that the contents are adequate and follow standard exercise guidelines for computer user. They also believe that the prototype is good to motivate and encourage users to exercise. This is because the exercise will pop-up on users' computer screen after several periods of using their computer based on their setting. The experts also suggested using animation or video to demonstrate the exercises, providing captionsfor images and providing clear narration of exercise instructions for the prototype improvement.

In the interface validation phase, two senior lecturers from UUM with at least five years of teaching and research experience in multimedia area validated the prototype. They reviewed the prototype based on the 11 proposed criteria gathered from the users. According to the experts, the prototype provides the users with appropriate and attractive media elements, giving user freedom and flexibility and encourage motivation for the user to use it. Both experts agreed that the healthy lifestyle prototype has the potential to motivate UUM community to exercise while using computers. To make it better, they suggested to further improve the prototype on its usability and interface design aspects.

\section{Conclusion}

Normally, the working hours of the UUM community are between 8 to 10 hours and computers are used to perform their work. Spending many hours using a computer without a break could cause a health problem to users. The perceptions that doing exercise requires a person to wear proper clothes and should only occur at a specific time are the biggest challenge in achieving a healthy lifestyle. A total of 11 criteria required by the user for healthy lifestyle application have been identified as - use cartoon / object / animation to guide the user while using the application; use graphics / images to give a brief overview of things / activities; provide audio / sound / background music; avoid time out (unlimited time) for any activity or exercise; provide encouragement / incentives words for motivation; display status of current activity; provide a forum for discussion; use soft and harmonious background colours; use readable font; provide enough time to learn something; and give the user freedom to 
answer question / perform activity. The developed prototype with all the identified criteria was validated by content and user interface experts. The experts responded positively towards the application.

\section{References}

[1] American Heart Association (2020). Flexibility Exercise (Stretching). Retrieved from https://www.heart.org/en/healthy-living/fitness/fitness-basics/flexibility-exercise-stretching

[2] American Heart Association (2020). American Heart Association Recommendations for Physical Activity in Adults and Kids. Retrieved from https://www.heart.org/en/healthyliving/fitness/fitness-basics/aha-recs-for-physical-activity-in-adults

[3] American Heart Association (2020). Strength and Resistance Training. Retrieved from https://www.heart.org/en/healthy-living/fitness/fitness-basics/strength-and-resistancetraining-exercise

[4] Aysha Khan, \& Faizin, (2016). Neck pain among computer user. Panacea Journal of Medical Sciences, 6 (2): 88-91.

[5] Exercises for Computer Users and office worker - USC. Retrieved from https://www.usc.edu.au/media/1000574/Exercises-for-Computer-Users-and-OfficeWorkers.pdf.

[6] Fabbro, A., Frankus, E., Kekale, C., Lawson, D. et al. (2011). Healthbox: Healthy Lifestyle through education. In Frankus, E. (Ed.), die Berater Human Concern, Austria.

[7] Garber, C. E., Blissmer, B., Deschenes, M. R., Franklin, B. A., Lamonte, M. J., Lee, I-Min, Nieman, D. C. \& Swain, D. P. (2011). Quantity and quality of exercise for developing and maintaining cardiorespiratory, musculoskeletal, and neuromotor fitness in apparently healthy adults: Guidance for prescribing exercise. Medicine and Science in Sport and Exercise, 43(7): 1334-1359. https://doi.org/10.1249/mss.0b013e318213fefb

[8] Gunduz, S. (2007). Health problem with the use of information technologies. Conference: International Educational Technology Conference. Retrieved from https://www.learntechlib.org/p/62152/.

[9] Hakala, P. T., Rimpela, A. H., Saarni, L. A. \& Salminen, J. J. (2006). Frequent computerrelated activities increase the risk of neck-shoulder and low back pain in adolescents. European Journal of Public Health, 16(5): 536-541. https://doi.org/10.1093/eurpub/ $\underline{\mathrm{ckl} 1025}$

[10] Hakala, P. T., Saarni, L. A., Ketola, R. L., Rahkola, E. T., Salminen, J. J. \& Rimpela, A. H. (2010). Computer-associated health complaints and sources of ergonomic instructions in computer-related issues among Finnish. BMC Public Health 2010, 10(11). https://doi.org/10.1186/1471-2458-10-11

[11] Healy, G. N., Dunstan, D. W., Salmon, J., et al. (2008). Break in sedentary time: beneficial association with metabolic risk. Diabetes Care, 3(14): 661-661.

[12] Kottke, T. E., Stiefel, M., \& Pronk, N. P. (2016). Well-being in all policies: promoting crosssectoral collabotation to improve people's lives. Preventing Chronic Disease and the National Academy of Medicine. https://doi.org/10.5888/pcd13.160155

[13] Lee, I. M., Sesso, H. D. Paffenbarger, R. S. (2000). Physical activity and coronary heart disease risk in men: does the duration ofexercise episodes predict risk? Circulation. (1029): 981-986. https://doi.org/10.1161/01.cir.102.9.981

[14] Logaraj, M. Madhupriya, V., Hegde, S. K. (2014). Computer vision syndrome and associated factors among medical and engineering students in Chennai. Ann Med Health Sci Res, 4: 179-185. https://doi.org/10.4103/2141-9248.129028 
[15] Office Ergonomic Guideline - Monash University (2017). Retrieved from https://www.monash.edu/ data/assets/pdf file/0020/147044/computer-user.pdf.

[16] Pollock, M. L., Gaesser, G. A., Butcher, J. D., Despres, J. P., Dishman, R. K., Franklin, B. A. \& Garber, C. E. (1998). ACSM: The recommended quantity and quality of exercise for developing and maintaining cardiorespiratory and muscular fitness, and flexibility in healthy adults. Medicine and science in sports and exercise, 30(6): 975-991. https://doi.org/10.1249/ 00005768-199806000-00032

[17] Shantakumari, N., Eldeeb, R., Sreedharan, J \& Gopal, K. (2014). Computer Use and VisionRelated Problems among university students in Ajman, United Arab Emirate. Annals of Medical \& Health Sciences Research, 4(2): 258-263. https://doi.org/10.4103/2141$\underline{9248.129058}$

[18] Sirajudeen, M. S., Muthusamy, H., Alqahtani, M., Waly, M. \& Jilani, A. K. (2018). Computer-related health problems among university students in Majmaah region, Saudi Arabia. Biomedical Research; 29(11): 2405-2415. https://doi.org/10.4066/ biomedicalresearch.61-18-418

[19] Sudharshini, S. Anantha Raman, V. V. \& Mathew Arumai, M. (2018). Computer Professionals and their health issues and managements. Public Health Review: International Journal of Public health Research, 5(3): 117-122. https://doi.org/10.17511/ijphr. 2018.i3.03

[20] The Board Resource Center \& in partnership with Eastern Los Angeles Regional Center. (2007). Guide to Healthy Living. Retrieved from www.brcenter.org.

[21] The U. S. Department of health and human services. Retrieved from https://www.hhs.gov/.

[22] Thomee, S., Harenstam, A. \& Hagberg, M. (2012). Computer use and stress, sleep disturbances, and symptoms of depression among young adults: a prospective cohort study. BMC Psychiatry, 12(176). https://doi.org/10.1186/1471-244x-12-176

[23] U. S. Department of Health and Human Services. (2018). Physical Activity Guidelines for Americans, 2 editions. Washington, DC: US.

[24] World Health Organization. (1999). Healthy Living: what is healthy lifestyle? Copenhagen: WHO Regional Office for Europe.

[25] Xuemei Yao, Shaobo Li, Yong Yao, Xiaoting Xie. (2018). Health Monitoring and Diagnosis of Equipment Based on Multi-sensor Fusion. International Journal of Online and Biomedical Engineering. 14(4): 4-19. https://doi.org/10.3991/ijoe.v14i04.8315

[26] Gahizi Emmanuel, Andi W.R. Emanuel, Djoko Budiyanto Setyohadi, (2020). Design of Mobile Application for Community Health Workers: A Case Study in Rwanda. International Journal of Interactive Mobile Technologies. 14(11): 271-279. https://doi.org/10.3991/ ijim.v14i11.13307

[27] Abdul Samad Dahri, Ahmad Al-Athwari, Azham Hussain. (2019). Usability Evaluation of Mobile Health Application from AI Perspective in Rural Areas of Pakistan. International Journal of Interactive Mobile Technologies. 13(11): 213-225. https://doi.org/10.3991/ ijim.v13i11.11513

\section{Authors}

Azliza Othman is a senior lecturer at School of Multimedia Technology and Communication, Universiti Utara Malaysia. Her areas of interest include Persuasive Technology, Multimedia Learning, Human Computer Interaction (HCI), and User Interface evaluation. mailto:azlizaman26@outlook.com 
Nassiriah Shaari is a senior lecturer at School of Multimedia Technology and Communication, Universiti Utara Malaysia. Her areas of interest include Web Information System, Accessibility and Universal Design, Human Computer Interaction (HCI), and User Experience (UX) evaluation.nasiriah@uum.edu.my

Yusrita Mohd Yusoff is a senior lecturer at School of Multimedia Technology and Communication, Universiti Utara Malaysia. Her areas of interest include Children Computer Interaction (CCI), Human Computer Interaction (HCI), Interaction Design for Children, and User Experience (UX) Evaluation.yusrita@uum.edu.my

Article submitted 2020-11-21. Resubmitted 2021-01-27. Final acceptance 2021-01-29. Final version published as submitted by the authors. 